\title{
INTERACTION OF CONCANAVALIN A WITH MODEL SUBSTRATES *
}

\author{
Irwin J. Goldstein, Cheryl M. Reichert, and Akira Misaki \\ Department of Biological Chemistry \\ The University of Michigan \\ Ann Arbor, Michigan 48104
}

During the last few years concanavalin $\mathrm{A}$ has become the most widely known and intensively investigated phytohemagglutinin. Much of this interest stems from the discovery that this lectin possesses several remarkable biological properties. In addition to its role as a hemagglutinin, ${ }^{1}$ a structural probe, ${ }^{2}$ and a mitogen, ${ }^{3-5}$ concanavalin $\mathrm{A}$ has been shown to restore normal growth patterns to transformed fibroblasts, ${ }^{6}$ to serve as an anticarcinogenic agent, ${ }^{7}$ and to distinguish between malignant and normal cells. ${ }^{4, "}$

First purified and crystallized by James Sumner, ${ }^{1.10}$ concanavalin $\mathrm{A}$ has been sequenced ${ }^{11-14}$ and its three-dimensional $x$-ray structure has been determined at the 2.0, 2.4, and $4 \AA$ levels. ${ }^{1-1 ;}$ The solution properties of this protein have also been studied in some detail. ${ }^{1-n 1}$ The results of the $\mathrm{x}$-ray analysis are in general accord with analytical ultracentrifugation ${ }^{18-20,22.26}$ and equilibrium dialysis studies. ${ }^{23 .}, 2.4$ The picture that has emerged is of a metalloprotein composed of subunits with a molecular weight of 27,000 ; each subunit possesses one sugar-binding site. At pH 5.5 and below, the protein exists as a dimer, molecular weight 54,000 . Above $\mathrm{pH} 5.5$ the protein dimers begin to aggregate, forming a tetramer with four binding sites.

The analogy between concanavalin A-macromolecule interaction and the antibody-antigen system, first noted by Sumner and Howell, ${ }^{1}$ has been commented upon by several investigators. ${ }^{31-3.5}$ In fact, the concanavalin A-carbohydrate interaction has been studied by means of a variety of immunochemical techniques: the quantitative precipitin reaction, ${ }^{36-39}$ the Landsteiner haptene inhibition technique, ${ }^{33,35,37,39-82}$ agar gel diffusion studies, ${ }^{37,43,44}$ and equilibrium dialysis measurements. ${ }^{23,}, 2$,

A chain-end mechanism was postulated to account for the precipitation reaction between concanavalin $A$ and certain specific, branched macromolecules, ${ }^{33,}, 37,10 .+1$ (for example, $\alpha$-D-glucans, $\alpha$-D-mannans and $\beta$-D-fructans). As indicated below, this generalization requires modification. A model of the chain-end mechanism is shown in Figure 1. Concanavalin $A$ is depicted as a tetrameric protein with four combining sites, each capable of interacting with specific, terminal glycosyl residues of polysaccharide or glycoprotein chain ends.

Since only neutral saccharides react with concanavalin $A$, it has been postulated that hydrogen bonding probably plays an important role in the binding phenomenon. $35,41,45,16$ Through the use of simple sugars and their derivatives as inhibitors of the concanavalin A-dextran interaction, it has been possible to ascertain the configurational features that a molecule must possess in order to bind to concanavalin A. In some instances it has been possible to

* This work was supported in part by National Institutes of Health research grant AM-10171 and United States Public Health Service training grant GM-00187. 


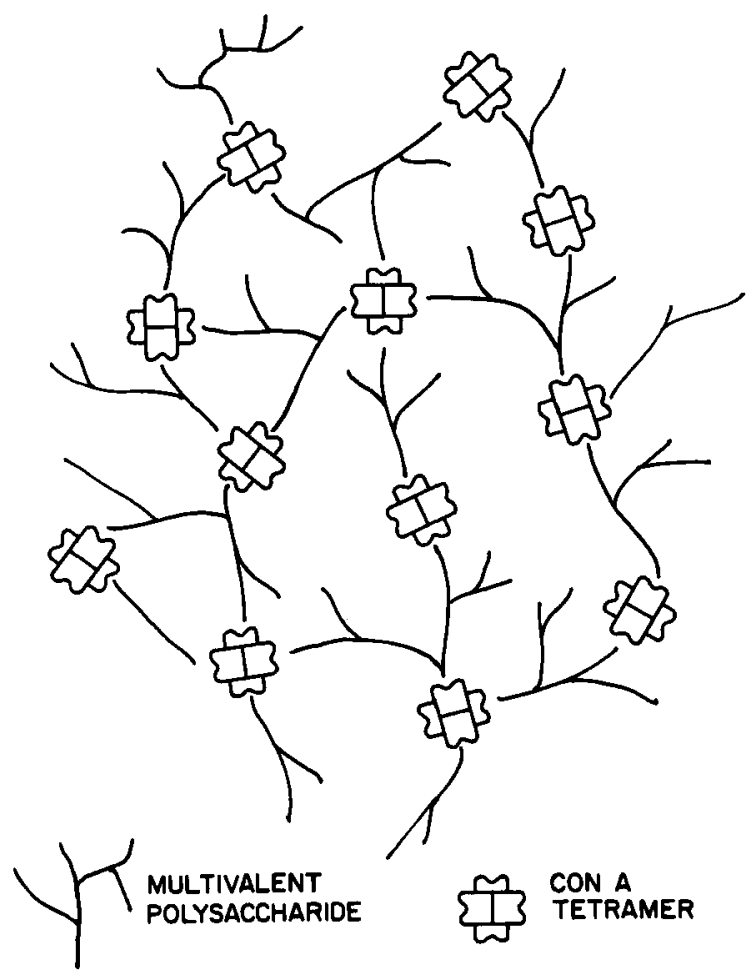

FIGURE 1. Chain-end mechanism of concanavalin A-polysaccharide interaction.

ascribe a role in the binding mechanism for individual $\mathrm{O}$ and $\mathrm{H}$ atoms of the various saccharide hydroxyl groups.

The simplest known substances that interact with the protein are 2-deoxy1,5-anhydro-D-arabino-hexitol ${ }^{34}$ and 1,4-anhydro-D-arabinitol ${ }^{42}$ (FIGURE 2). There are remarkable similarities in the angular dispositions of the hydroxyl groups of these two ring systems. ${ }^{34}$ Any modification of the crucial hydroxyl groups at C-3, C-4, and C-6 of the tetrahydropyran ring or at C-2, C-3, and $\mathrm{C}-5$ of the tetrahydrofuran ring (for example, a change in configuration or a conversion to a deoxy or $O$-methyl ether derivative) drastically reduces or abolishes interaction with the protein ${ }^{34,40,42}$ Sugars that are configurationally related to these structures will also interact with concanavalin $A$. The names of several of these carbohydrates are listed beneath their respective prototypes in Figure 2. Concanavalin A has also been shown to have a high degree of specificity for the $\alpha$-configuration at the anomeric (C-1) carbon atom of the D-pyranose ring system. ${ }^{34,35,40,41}$

There is a striking parallel between the simple sugars bound by concanavalin $\mathbf{A}$ and the monosaccharides that serve as substrates for yeast hexokinase (see Figure VI.3 in Dixon and Webb's treatise Enzymes ${ }^{47}$ ). Although nothing definitive is known regarding a possible physiological role for concanavalin A within the jack bean, it is tempting to postulate an enzymatic activity for 
concanavalin A. However, we have been unable to detect any hexokinase, phosphatase, or phosphorylase activity for this protein.

Although the $\alpha$-methylglycoside of 2-deoxy-D-glucose (methyl 2-deoxy- $\alpha$ D-arabino-hexopyranoside) binds to concanavalin A, the addition of an axial hydroxyl group (a D-manno-configuration) enhances the affinity of the saccharide for concanavalin A threefold. An equatorial C-2 hydroxyl group (a D-gluco-configuration) destabilizes the carbohydrate-protein complex, probably through steric hindrance 3.41 (TABLE 1). From these data it may be deduced that there exists on the protein a locus that reacts specifically with the C-2 hydroxyl group of D-mannose. In order to identify the precise atom(s) of the C-2 hydroxyl group that may be involved in binding to the protein, several derivatives of D-mannose modified at the $\mathrm{C}-2$ position were tested.41 The 2-O-methyl derivatives of $\mathrm{D}$-mannose bind as well as the parent sugar (TABLE 1). Furthermore, 2-deoxy-2-fluoro-D-mannose is a somewhat better inhibitor than D-mannose. Since a fluorine atom is isosteric with an hydroxyl group and is known to participate in hydrogen bond formation, ${ }^{48}$ we suggest that it is the $O$-atom of the C-2 hydroxyl group of D-mannose that is involved in noncovalent bonding to the protein.

The effect of modifying the C-3 hydroxyl group of D-glucose has already been reported. ${ }^{41}$ The data in TABLE 1 indicate that a C-3 equatorial hydroxyl group is required, that there is a relatively close fit between the protein and this hydroxyl group, and that it is the $\mathrm{O}$-atom of the $\mathrm{C}-3$ hydroxyl group that participates in H-bonding to the protein.

An equatorial hydroxyl group at the C-4 position of D-glucose or D-mannose

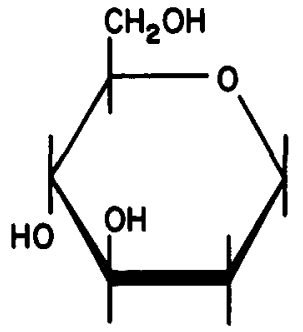

2-Deoxy - I, 5-Anhydroo-Arabino-Hexitol

$\alpha-D$-Glucopyranose

$\alpha-D$-Mannopyranose

$\alpha-L-$ Sorbopyranose

$\beta-D$-Fructopyranose

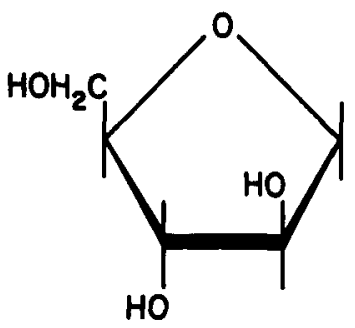

1,4-Anhydro-D-Arabinitol

$\alpha-0$-Arabinofuranose

$\beta-D$-Arabinofuranose

$\beta-D$-Fructofuranose

$\alpha-D$-Fructofuronose

Figure 2. Structures of 2-deoxy-1,5-anhydro-D-arabino-hexitol and 1,4-anhydro-Darabinitol, demonstrating the minimum configurational features required for binding to concanavalin A. Sugars with related structures are listed beneath their respective prototypes. 
TABle 1

Inhibiting Power of Various Saccharides *

\begin{tabular}{|c|c|}
\hline & $\begin{array}{l}\text { Quantity Needed } \\
\text { for } 50 \% \\
\text { Inhibition } \dagger\end{array}$ \\
\hline $\begin{array}{l}\text { Compound } \\
\text { Methyl 2-deoxy- } \alpha \text {-D-arabino-hexopyranoside } \\
\text { Methyl } \alpha \text {-D-mannopyranoside } \\
\text { Methyl } \alpha \text {-D-glucopyranoside }\end{array}$ & $\begin{array}{l}\mu \mathrm{mol} \\
0.95 \\
0.34 \\
1.30\end{array}$ \\
\hline $\begin{array}{l}\text { D-Mannose } \\
\text { 2-O-Methyl-D-mannose } \\
p \text {-Nitrophenyl- } \alpha \text {-D-mannopyranoside } \\
p \text {-Nitrophenyl-2- } O \text {-methyl- } \alpha \text {-D-mannopyranoside } \\
\text { 2-Deoxy-2-fluoro-D-mannose }\end{array}$ & $\begin{array}{l}2.0 \\
1.9 \\
0.17 \\
0.19 \\
1.5\end{array}$ \\
\hline $\begin{array}{l}\text { D-Glucose } \\
\text { 3-Deoxy-D-ribo-hexopyranose } \\
\text { 3-Deoxy-3-fluoro-D-glucose }\end{array}$ & $\begin{array}{l}11.3 \\
40(0) \\
16.3\end{array}$ \\
\hline $\begin{array}{l}\text { Methyl } \alpha \text {-D-glucopyranoside } \\
\text { Methyl } \alpha \text {-D-galactopyranoside } \\
\text { Methyl 4-deoxy- } \alpha \text {-D-xylo-hexopyranoside } \\
\text { Methyl 4- } O \text {-methyl } \alpha \text {-D-glucopyranoside } \\
\text { D-Glucose } \\
\text { 4-Deoxy-4-fluoro-D-glucose } \\
\text { Methyl } \alpha \text {-D-glucopyranoside } \\
\text { Methyl } \alpha \text {-D-xylopyranoside } \\
\text { Methyl 6-deoxy- } \alpha \text {-D-glucopyranoside } \\
\text { Methyl 6-deoxy-6-fluoro- } \alpha \text {-D-glucopyranoside }\end{array}$ & $\begin{array}{l}1.3 \\
200(0) \\
99(0) \\
200(0) \\
25 \\
50(0) \\
2.5 \\
104(1) \\
59(2) \\
35(19)\end{array}$ \\
\hline $\begin{array}{l}\text { 1,5-Anhydro-D-glucitol } \\
\text { Methyl } \alpha \text {-D-glucopyranoside } \\
\text { Methyl } \beta \text {-D-glucopyranoside }\end{array}$ & $\begin{array}{r}7.2 \\
1.3 \\
37.0\end{array}$ \\
\hline $\begin{array}{l}\text { D-Glucose } \\
\alpha \text {-D-Glucopyranosyl fluoride }\end{array}$ & $\begin{array}{l}25 \\
25\end{array}$ \\
\hline
\end{tabular}

* Because these data were collected in a series of experiments over a long time period, ${ }^{35,}{ }^{41,42}$ only the numerical values within each set may be directly compared.

$\uparrow$ Where numbers are given in parentheses, $50 \%$ inhibition was not attained; the numbers in parentheses indicate the percent inhibition given by the $\mu$ mol saccharide noted. 


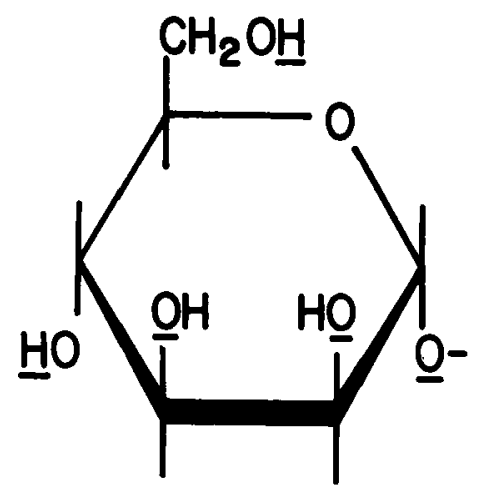

Figure 3. Sugar-binding specificity of concanavalin $A$. The hydrogen and oxygen atoms thought to participate in the interaction with concanavalin $\mathbf{A}$ are underlined.

is an absolute necessity. ${ }^{41}$ Any modification of this hydroxyl group abolishes the capacity of the sugar to bind to concanavalin A. Thus, methyl $\alpha$-D-galactopyranoside, methyl 4-O-methyl- $\alpha$-D-glucopyranoside, and 4-deoxy-4-fluoroD-glucose do not inhibit concanavalin A-polysaccharide interaction. These data point to a very close fit between the protein and the C-4 hydroxyl group, and indicate that it is the $\mathrm{H}$-atom of this hydroxyl group that binds to the protein.

A study of the effects of alterations of the C-6 hydroxymethyl group of D-glucose has also been published. ${ }^{35}$ Neither methyl $\alpha$-D-xylopyranoside (which lacks a C-6 hydroxymethyl group) nor methyl 6-deoxy- $\alpha$-D-glucopyranoside (which lacks a C-6 hydroxyl group) binds to concanavalin $A$. The $\alpha$-methyl glycoside of 6-deoxy-6-fluoro-D-glucose is a very poor inhibitor of the concanavalin A system. On the basis of these studies it was concluded ${ }^{35}$ that an

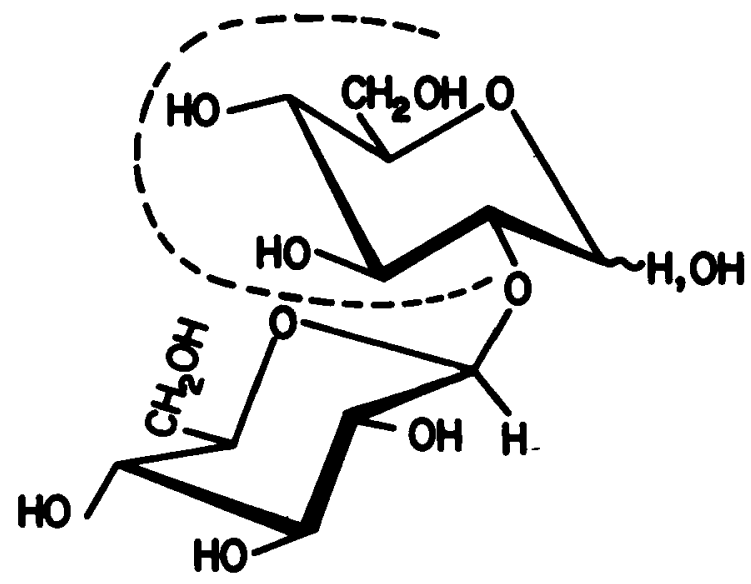

Figure 4. Structure of sophorose (2-O- $\beta$-D-glucopyranosyl-D-glucose). The site of interaction with concanavalin $A$ is outlined. 


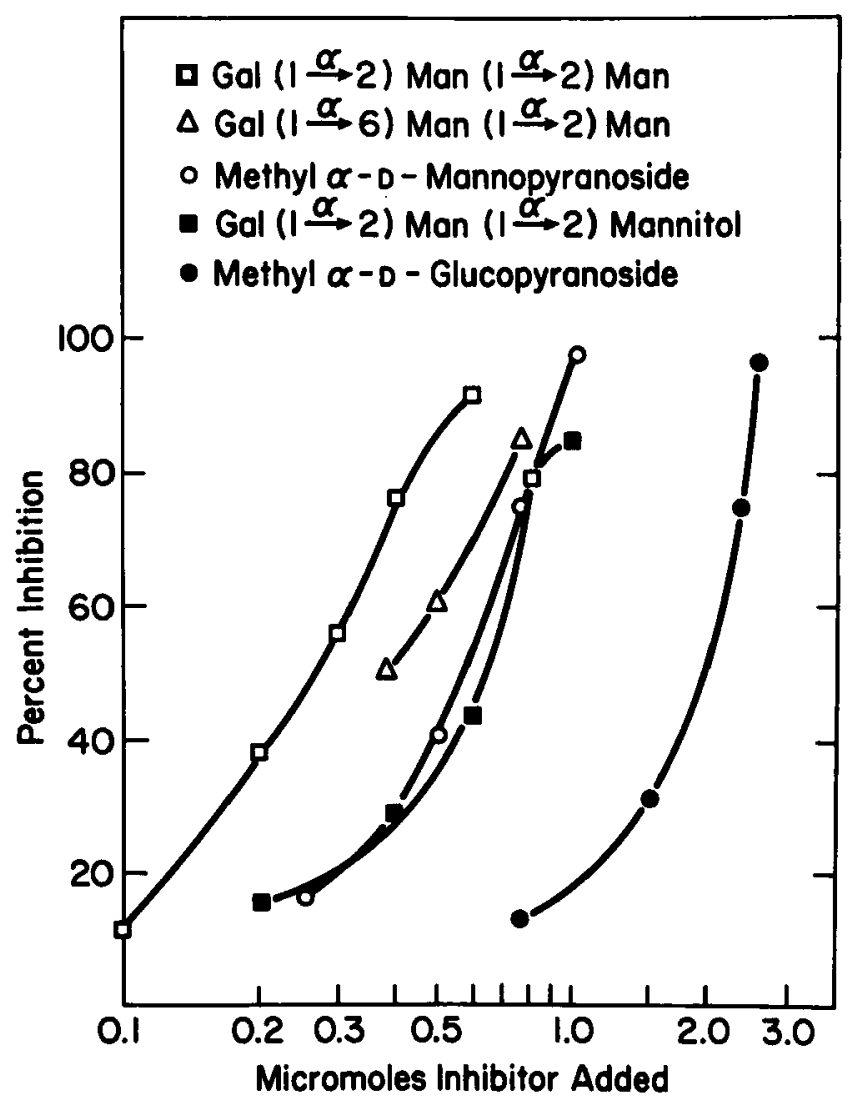

FiguRE 5. Inhibition of concanavalin A-dextran B-1355-S interaction by saccharides. $\square=O-\alpha$-D-galactopyranosyl-( $1 \rightarrow 2)-O$ - $\alpha$-D-mannopyranosyl-( $1 \rightarrow 2)$-D-mannose; $\Delta=O$ - $\alpha$-D-galactopyranosyl-( $1 \rightarrow 6)-O$ - $\alpha$-D-mannopyranosyl-( $1 \rightarrow 2)$-D-mannose; $\quad O=$ methyl $\alpha$-D-mannopyranoside; $\quad=O$ - $\alpha$-D-galactopyranosyl- $(1 \rightarrow 2)-O$ - $\alpha$-D-mannopyranosyl-( $1 \rightarrow 2)$-D-mannitol; $=$ methyl $\alpha$-D-glucopyranoside. Each tube contained concanavalin A $(340 \mu \mathrm{g})$, dextran B-1355-S $(600 \mu \mathrm{g})$, and inhibitor as noted, in a total volume of $3.0 \mathrm{ml}$.

unmodified C-6 hydroxymethyl group is required, and it is the H-atom of the C-6 hydroxyl group that forms an $\mathrm{H}$-bond with concanavalin $\mathbf{A}$.

As already indicated, concanavalin $\mathbf{A}$ exhibits a marked preference for the $\alpha$-configuration at the $\mathrm{C}-1$ position of the D-pyranose ring (TABLE 1). Recently it was shown in our laboratory that $\alpha$-D-glucopyranosyl fluoride is equivalent to D-glucose as an inhibitor of concanavalin A-dextran precipitation (TABLE 1). One possible interpretation is that the $\mathrm{O}$-atom at the $\mathrm{C}-1$ position may be involved in binding to the protein.

A summary of the conclusions that may be suggested by the above data is presented in FIGURE 3. The generalization we initially formulated (the possession of unmodified hydroxyl groups at the C-3, -4 , and -6 positions of the 
$\alpha$-D-glucopyranosyl or $\alpha$-D-mannopyranosyl ring system) appears to be the broadest possible formulation of the configurational requirements for the binding of carbohydrates to concanavalin A. Nevertheless, it has become necessary to modify the original concept of an exclusive chain-end mechanism to account for all concanavalin A-carbohydrate interactions. A number of years ago Hehre anticipated this modification when he noted that internal 2-O-linked $\alpha$-D-glucopyranosyl units present in various dextrans possess the minimal configurational features necessary for binding to the protein. ${ }^{32 .} \cdot 19$

The data that forced reexamination of the concept of an exclusive chainend interaction included inhibition studies in which model oligosaccharides were used ${ }^{50,51}$ and reports ${ }^{52-54}$ that certain glycopeptides which lack terminal nonreducing $\alpha$-D-gluco- and $\alpha$-D-mannopyranosyl residues interact with concanavalin $A$. The experimental observation which provided the first indication that internal residues could bind to concanavalin $A$ was the finding that the $\beta$-glucobiose sophorose (2-O- $\beta$-D-glucopyranosyl-D-glucose) inhibited concanavalin A-dextran interaction. ${ }^{50}$ Figure 4 shows the structure of sophorose and its site of reaction with concanavalin A.

Inhibition data also support the conclusion that internal 2-O-linked $\alpha$-Dmannopyranosyl units may bind to concanavalin $A^{51}$ The two trisaccharides $O$ - $\alpha$-D-galactopyranosyl- $(1 \rightarrow 2)-O$ - $\alpha$-D-mannopyranosyl- $(1 \rightarrow 2)$-D-mannose and $O$ - $\alpha$-D-galactopyranosyl- $(1 \rightarrow 6)-O$ - $\alpha$-D-mannopyranosyl-( $1 \rightarrow 2)$-D-mannose each possess a terminal, nonreactive $\alpha$-D-galactopyranosyl unit, yet both are more potent inhibitors of the concanavalin A-dextran system than methyl $\alpha$-Dmannopyranoside (FIGURE 5). Reduction with $\mathrm{NaBH}_{4}$ of the former trisaccharide yields the corresponding trisaccharide alditol, which still possesses considerable inhibitory potency due to the presence of an internal $\alpha-(1 \rightarrow 2)$ D-mannopyranosyl unit.

In addition, previously reported inhibition data on mannose oligosaccharides ${ }^{37}$ show that inhibitory potency increases as the sequence of $\alpha-(1 \rightarrow 2)$ -
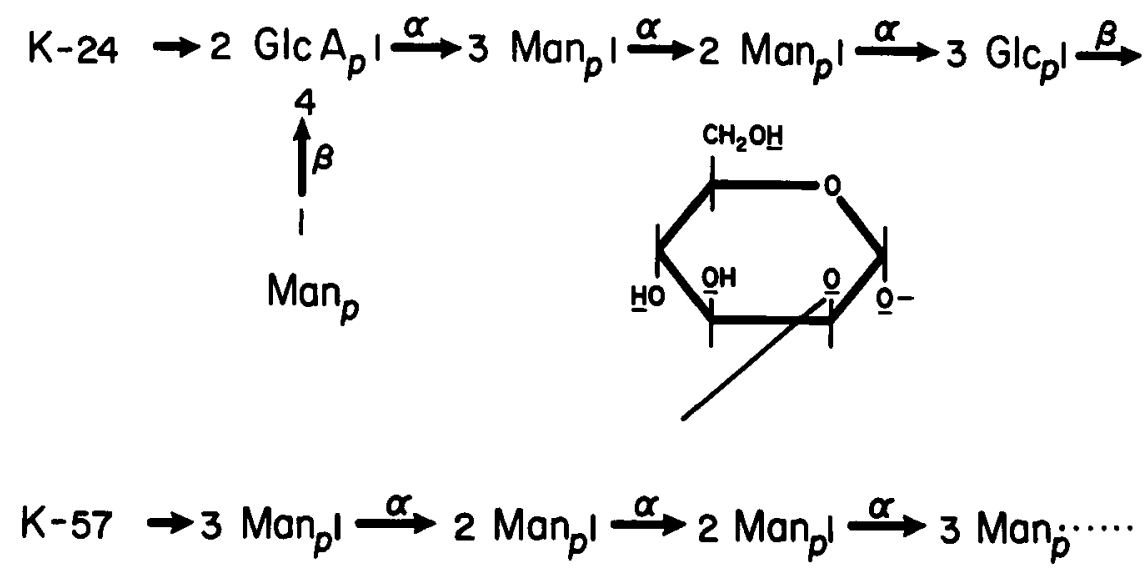

FIGURE 6. Interaction of concanavalin A with Klebsiella polysaccharides, types K-24 and K-57; structure of K-24 and K-57 together with the structure of a 2-Olinked $\alpha$-D-mannopyranosyl unit. 
linked D-mannopyranosyl units is extended, the mannotriose and mannotetraose being approximately 20 times more inhibitory than methyl $\alpha$-D-mannopyranoside. ${ }^{55}$ These data not only support the postulated binding of the protein to internal glycosyl units but also raise the question of the precise size of the concanavalin A combining site.

Further support for the reactivity of internal 2-O-linked $\alpha$-D-mannopyranosyl groups comes from precipitation studies with macromolecules of known structure. Through the kindness of several investigators, we have obtained samples of several Klebsiella polysaccharides, some of which contain internal 2-O-linked $\alpha$-D-mannopyranosyl units. FIGURE 6 shows the structure of two of these: K-24 (Choy and colleagues ${ }^{56}$ ) and K-57 (Lindbergh and colleagues ${ }^{57}$ ). Both contain internal 2-O-linked $\alpha$-D-mannopyranosyl units as the only glycosyl units potentially capable of interacting with concanavalin $A$. FIGURE 7 presents a gel diffusion study of the interaction of concanavalin A with these two polysaccharides, both of which give precipitin bands; $\mathrm{K}-11$,

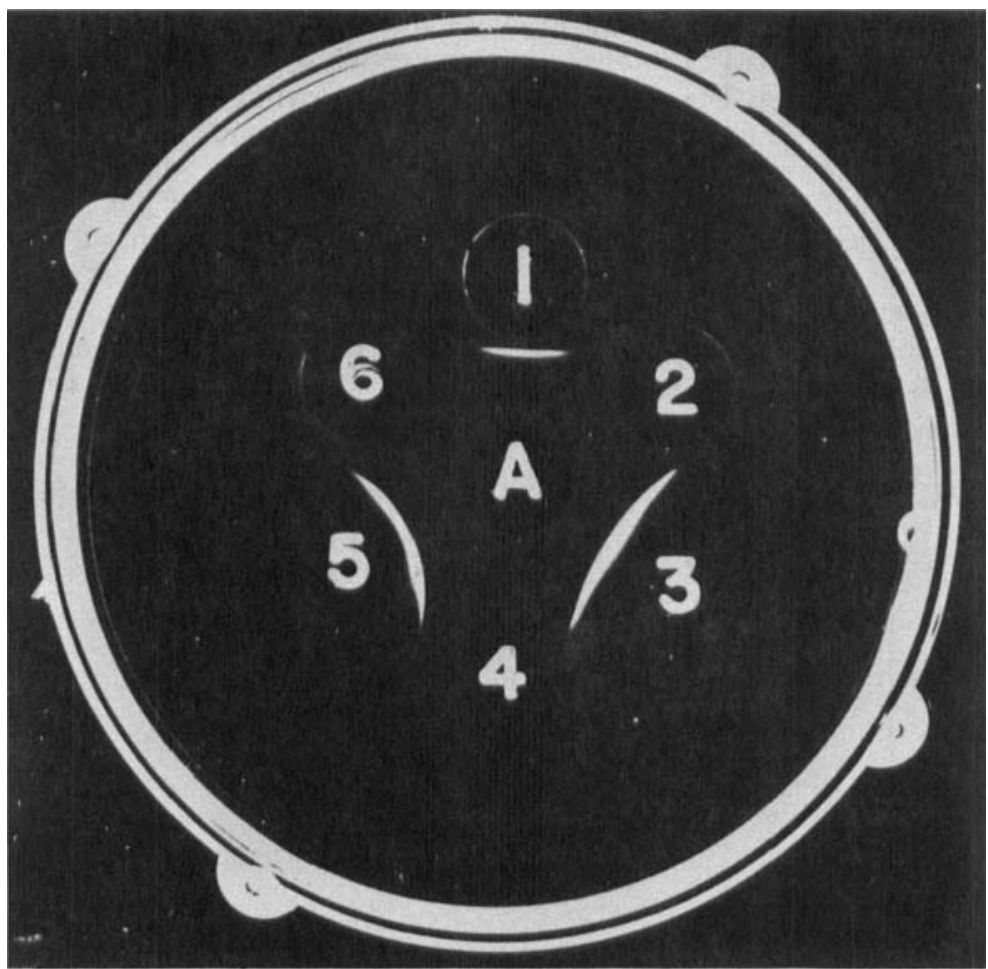

Figure 7. Agar gel diffusion pattern of the interaction of some Klebsiella polysaccharides with concanavalin A. Central well (A) contains concanavalin A (4 mg/ $\mathrm{ml})$. The peripheral wells contain: (1) Klebsiella K-24 (1 mg/ml); (2) Klebsiella K-11 (1 mg/ml); (3) Klbesiella K-57 (0.66 mg/ml); (4) $0.15 \mathrm{M} \mathrm{NaCl}$; (5) dextran B-1355-S (1 mg/ml). 


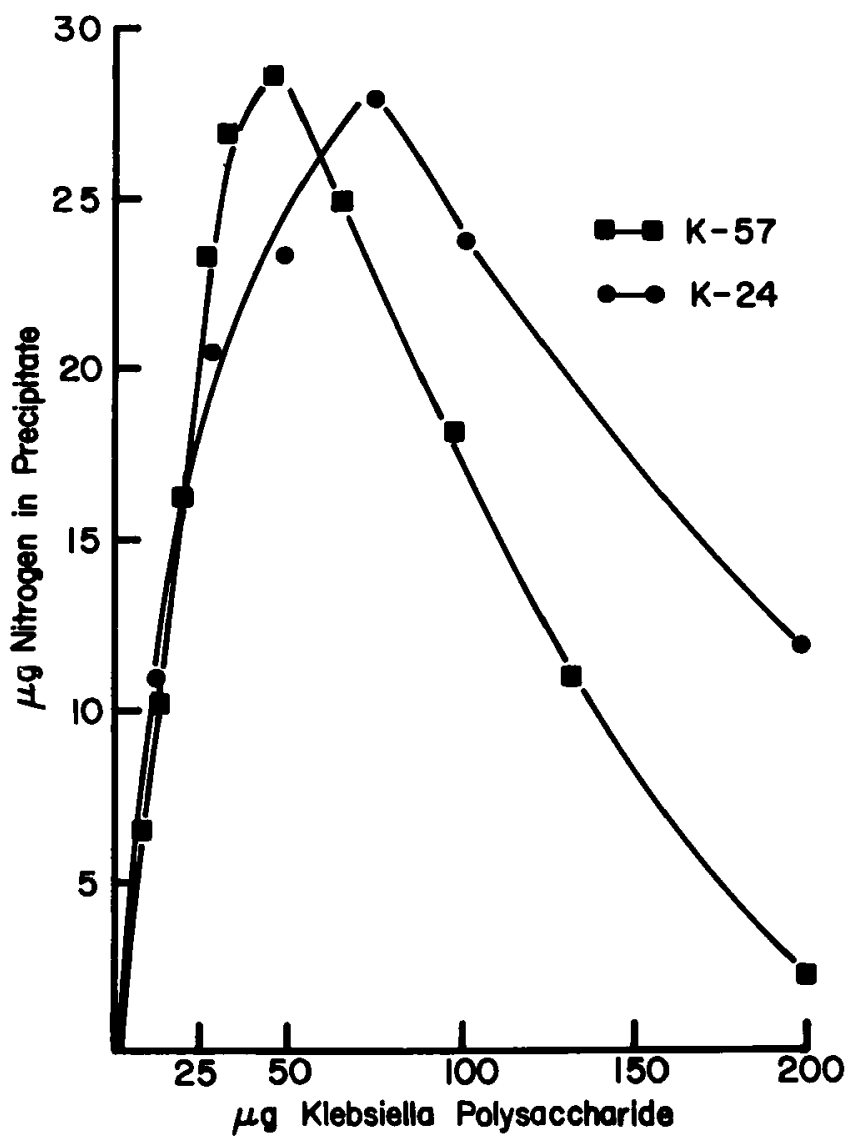

FIGURE 8. Quantitative precipitation curves of concanavalin A (46 $\mu \mathrm{g}$ nitrogen) with Klebsiella polysaccharides K-57 (a) and K-24 (O).

which has no concanavalin A sugar-reactive units, fails to react. Dextran B1355-S, our reference polysaccharide, $31 ; .13$ serves as a positive control.

The precipitin curves generated when concanavalin A interacts with Klebsiella polysaccharides K-24 and K-57 are presented in Figure 8. The K-57 polysaccharide, which possesses blocks of two consecutive $\alpha-(1 \rightarrow 2)$-D-mannopyranosyl units within its structure, gives a more pronounced precipitin band than K-24 in Ouchterlony plates (FIGURE 7) and reaches equivalence at a slightly lower polysaccharide concentration.

The ability of concanavalin $A$ to bind to internal $\alpha$-mannopyranosyl units does not appear to be limited to polysaccharides. A thyroglobulin glycopeptide with no terminal sugars capable of binding to concanavalin A was shown by Osawa and colleagues $5: 3$ to inhibit the hemagglutination of erythrocytes by concanavalin A.

Most of the phytohemagglutinins that have been isolated in pure form have been shown to be glycoproteins. ${ }^{31}$ (Concanavalin $\mathrm{A}^{1-20}$ and the wheat germ 


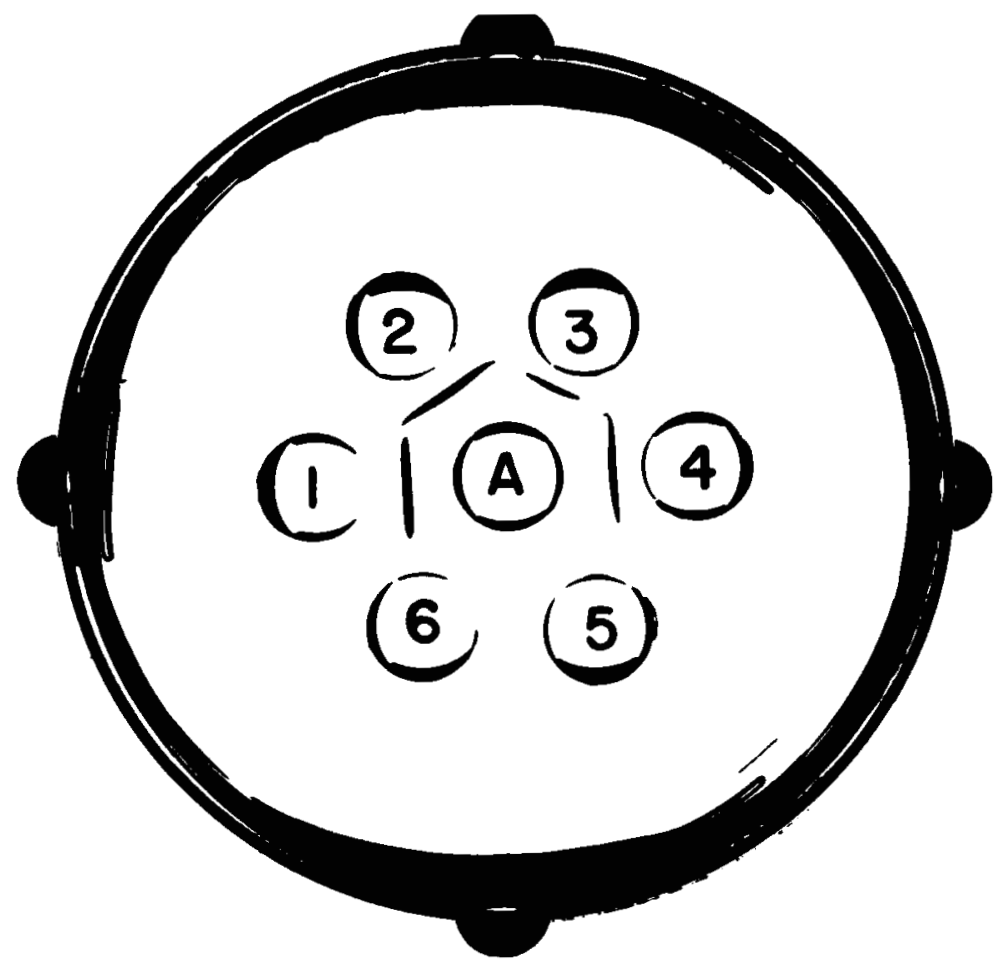

FigURE 9. Agar gel diffusion pattern of the interaction of concanavalin A with various phytohemagglutinins. The central well (A) contains concanavalin $A(4 \mathrm{mg} /$ $\mathrm{ml})$. The peripheral wells contain: (1) Bandeiraea simplicifolia lectin $(2.0 \mathrm{mg} / \mathrm{ml})$; (2) wax bean lectin from Phaseolus vulgaris $(1.0 \mathrm{mg} / \mathrm{ml}) ;(3)$ soybean lectin from Glycine $\max (1.25 \mathrm{mg} / \mathrm{ml})$; (4) lima bean lectin from Phaseolus lunatus $(1.1 \mathrm{mg}$ / $\mathrm{ml})$; (5) wheat germ agglutinin from Tritium vulgaris $(0.75 \mathrm{mg} / \mathrm{ml}) ;(6) 0.15 \mathrm{M}$ $\mathrm{NaCl}$.

agglutinin 58 are notable exceptions.) Several years ago we discovered that concanavalin A will precipitate many other lectins from solution..$^{59}$ The observation that concanavalin A interacts with other lectins of glycoprotein origin has been adapted to a general procedure for the isolation of phytohemagglutinins reactive with concanavalin $\mathbf{A}^{\mathrm{B} 0}$ The ability of concanavalin $\mathrm{A}$ to form an agar gel precipitin band with several glycoprotein lectins is demonstrated in Figure 9.

The carbohydrate composition of several glycoprotein lectins has been investigated. $^{3 t}$ Almost all of them are reported to contain D-mannose and $\mathrm{N}$-acetylD-glucosamine among their sugar components. Although both of these sugars are potentially capable of reacting with concanavalin $A$, only the mannose is thought to participate in the concanavalin A-lectin interaction. The carbohydrate moiety of the soybean lectin was studied by Lis, ${ }^{01,62}$ who used jack bean $\alpha$-mannosidase to demonstrate the presence of $\alpha$-D-mannopyranosyl units. Using a series of purified glycosidases and methylation analysis, Misaki has 


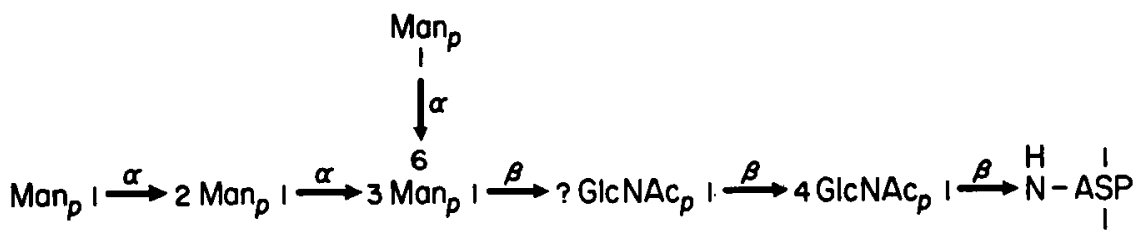

FIGURE 10. Tentative diagram of the structure of the lima bean lectin glycopeptide. . $^{\text {us }}$

sequenced the carbohydrate portion of the lima bean lectin. ${ }^{\text {i3 }} \mathrm{A}$ tentative diagram of the structure is presented in FIgURE 10. The internal 2-O-linked $\alpha$-D-mannopyranosyl residue and the two terminal $\alpha$-D-mannopyranosyl units are potential receptor sites for concanavalin $A$ in its interaction with the lima bean lectin. In those cases in which structural studies have been conducted on the carbohydrate moiety of lectins, ${ }^{31} N$-acetyl-D-glucosamine has been ruled out as a concanavalin A binding locus, both because of its $\beta$-glycosyl linkage and its location in the core of the oligosaccharide chain.

These studies lead to the conclusion that in addition to binding to saccharide chain ends of the appropriate configuration, concanavalin $A$ will also react with internal 2-O-substituted $\alpha$-D-mannopyranosyl units. Accessible, internal 2 - $O$-linked $\alpha$-D-glucopyranosyl residues may also bind to the protein. This observation is helpful to the interpretation of the interaction of concanavalin $A$ with naturally occurring glycopeptides, ${ }^{, 3}$ glycoproteins, ${ }^{59,64-6 i}$ synthetic carbohydrate-protein conjugates, ${ }^{6 \%, 69}$ and cellular surfaces. ${ }^{70,} ; 1$

\section{ACKNOWLEDGMENTS}

We are indebted to the following colleagues for samples of polysaccharides and carbohydrate inhibitors: Professor G. Dutton, University of Vancouver, Canada, for Klebsiella K-24; Professor Bengt Lindberg, University of Stockholm, Sweden, for Klebsiella K-57; Dr. S. Stirm, Max-Planck Institut für Immunbiologie, Freiburg, West Germany, for Klebsiella K-11; Professor A. B. Foster, Chester Beatty Institute, London, for 2-deoxy-2-fluoro-D-mannose; Dr. C. F. Curtis, Albert Einstein College of Medicine, New York, for 4-deoxy4-fluoro-D-glucose; and Professor E. Hehre, Albert Einstein College of Medicine, New York, for $\alpha$-D-glucopyranosyl fluoride.

\section{REFERENCES}

1. Sumner, J. B. \& S. F. Howell. 1936. J. Bacteriol. 32: 227-237.

2. Goldstein, I. J. 1972. In Methods in Carbohydrate Chemistry. Vol. VI. R. Whistler \& J. BeMiller, Eds. : 106-119. Academic Press Inc. New York, N.Y.

3. Wecksler, M., A. Levy y Werner \& G. Jaffe. 1968. Acta Cient. Venezolana 19: $154-156$.

4. Beckert, W. H. \& M. M. Sharkey, 1970. Intern. Arch. Allergy Appl. Immunol. 39: 337-341.

5. Powell, A. E. \& M. A. Leon. 1970. Exp. Cell Res. 62: 315-325.

6. Burger, M. M. \& K. D. Noonan. 1970. Nature 228: 512-515.

7. Shoham, J., M. INbar \& L. Sachs. 1970. Nature 227: 1244-1246. 
8. INBAR, M. \& L. SACHS. 1969. Nature 223: 710-712.

9. Inbar, M. \& L. SAchs. 1969. Proc. Nat. Acad. Sci. U.S. 63: 1418-1425.

10. Sumner, J. B. 1919. J. Biol. Chem. 37: 137-142.

11. Wang, J. L., B. A. Cunningham \& G. M. Edelman. 1971. Proc. Nat. Acad. Sci. U.S. 68: 1130-1134.

12. Edmundson, A. B., K. R. Ely, D. A. Sly, F. A. Westholm, D. A. Powers \& I. E. LIENER. 1971. Biochemistry 10: 3554-3559.

13. Waxdol, M. J., J. L. Wang, M. N. Pflumm \& G. M. Edelman. 1971. Biochemistry 10: 3343-3347.

14. Edelman, G. M., B. A. Cunningham, G. N. Reeke, JR., J. W. Becker, M. J. Waxdol \& J. L. Wang. 1972. Proc. Nat. Acad. Sci. U.S. 69: 2580-2584.

15. Hardman, K. D., M. K. Wood, M. Schiffer, A. B. Edmundson \& C. F. AinsWORTH. 1971. Proc. Nat. Acad. Sci. U.S. 68: 1393-1397.

16. Quiocho, F. A., G. N. ReEke, JR., J. W. Becker, W. N. Lipscomb \& G. M. Edelman. 1971. Proc. Nat. Acad. Sci. U.S. 68: 1853-1857.

17. HaRdman, K. D. \& C. F. Ainsworth. 1972. Biochemistry 11: 4910-4919.

18. Olson, M. O, J. \& I. E. Liener. 1967. Biochemistry 6: 105-111.

19. Agrawal, B. B. L. \& I. J. Goldstein. 1967. Biochim. Biophys. Acta 133: 376379.

20. Agrawal, B. B. L. \& I. J. Goldstein. 1968. Arch. Biochem. Biophys. 124: 218229.

21. Olson, M. O. J. \& I. E. Liener. 1967. Biochemistry 6: 3801-3808.

22. Kalb, A. J. \& A. Lustig. 1968. Biochim. Biophys. Acta 168: 366-367.

23. Yariv, J.. A. J. Kalb \& A. Levitzki. 1968. Biochim. Biophys. Acta 165: 303305.

24. So, L. L. \& I. J. GoldsteIn. 1968. Biochim. Biophys. Acta 165: 398-404.

25. McKenzie, G. H., W. H. SAWyer \& L. W. Nichol. 1972. Biochim. Biophys. Acta 263: 283-293.

26. Sumner, J. B., N. Gralén \& I-B. Eriksson-Quensel, 1938. J. Biol. Chem. 125: $45-48$.

27. Pflumm, M. N., J. L. Wang \& G. M. Edelman. 1971. J. Biol. Chem. 246: 4369-4370.

28. Zand, R., B. B. L. Agrawal \& I. J. Goldstein. 1971. Proc. Nat. Acad. Sci. U.S. 68: 2173-2176.

29. KAY, C. 1970. FEBS Letters 9: 78-80.

30. Entlicher, G., J. V. Koštír \& J. Kocourek. 1971. Biochim. Biophys. Acta 236: 795-797.

31. Sharon, N. \& H. Lis. 1971. Science 177: 949-959.

32. Hehre, E. J. 1960. Bull. Soc. Chim. Biol. 42: 1581-1585.

33. Goldstein, I. J., C. E. Hollerman \& J. M. Merrick. 1965. Biochem. Biophys. Acta 97: 68-76.

34. Goldstein, I. J., C. E. Hollerman \& E. E. Smith. 1965. Biochemistry 4: 876883.

35. So, L. L. \& I. J. Goldstein. 1967. J. Immunol. 99: 158-163.

36. So, L. L. \& I. J. Goldstein. 1967. J. Biol. Chem. 242: 1617-1622.

37. So, L. L. \& I. J. Goldstein, 1968. J. Biol. Chem. 243: 2003-2007.

38. Goldstein, I. J., R. D. Poretz, L. L. So \& Y. Yang. 1968. Arch. Biochem. Biophys. 127: 787-794.

39. Lloyd, K. O., E. A. Kabat \& S. Beychok. 1969. J. Immunol. 102: 1354-1362.

40. SMith, E. E. \& I. J. Goldstein. 1967. Arch. Biochem. Biophys. 121: 88-95.

41. Poretz, R. D. \& I. J. Goldstein. 1970. Biochemistry 9: 2890-2896.

42. So, L. L. \& I. J. Goldstein. 1969. Carbohydr. Res. 10: 231-244.

43. Goldstein, I. J. \& L. L. So. 1965. Arch. Biochem. Biophys. 111: 407-414.

44. So, L. L. \& I. J. GoldsteIN. 1969. J. Immunol, 102: 53-57.

45. Doyle, R. J., E. E. Woodside \& C. W. Fishel. 1968. Biochem. J. 106: 35-40.

46. Doyle, R. J., E. P. Pittz \& E. E. Woodside. 1968. Carbohydr. Res. 8: 89-100. 
47. Dixon, M. \& E. C. Webb. 1964. Enzymes, 2nd ed., p. 217. Academic Press Inc. New York, N.Y.

48. Pauling, L. 1960. The Nature of the Chemical Bond, pp. 449-450. Cornell University Press. Ithaca, N.Y.

49. Hehre, E. J. 1964. Kagaku no Royoiki 9: 454-455.

50. Goldstein, I. J., R. N. IYer, E. E. SMITH \& L. L. So. 1967. Biochemistry 6: 2373-2377.

51. Goldstein, I. J., C. M. Reichert, A. Misaki \& P. A. J. Gorin. 1973. Biochim. Biophys. Acta 317: 500-504.

52. Kornfeld, S., J. Rogers \& W. Gregory, 1971. J. Biol. Chem. 246: 6581-6586.

53. Toyoshima, S., M. Fukuda \& T. Osawa. 1972. Biochemistry 11: 4000-4005.

54. Presant, C. A. \& S. Kornfeld. 1972. J. Biol. Chem. 247: 6937-6945.

55. So, L. L. \& I. J. GoldsteIN. Unpublished data.

56. Choy, Y. M., G. G. S. Dutton \& A. B. Zanlungo. 1973. Can. J. Chem. 51: 1819-1826.

57. Lindberg, B., J. Lonngren \& W. Nimmich, 1972. Acta Chem. Scand. 26: 22312236.

58. Allen, A. K., A. Neuberger \& N. Sharon, 1973. Biochem. J. 131: 155-162.

59. Goldstein, I. J., L. L. So, Y. Yang \& Q. C. Callies. 1969. J. Immunol. 103: 695-698.

60. Bessler, W. \& I. J. Goldstein. FEBS Letters 34: 58-62.

61. Lis, H., N. Sharon \& E. Katchalski. 1966. J. Biol. Chem. 241: 684-689.

62. Lis, H. 1968. Proc. Israel J. Chem. 6: 114.

63. MisakI, A. \& I. J. GoldsteIn. Unpublished data.

64. Nakamura, S., K. Tanaka \& S. Murakawa. 1960. Nature 188: 144-145.

65. HARris, H. \& E. B. RobSON. 1963. Vox Sanguinis 8: 348-355.

66. LEON, M. A. 1967. Science 158: 1325-1326.

67. ANDERSEN, B. R. 1969. Immunochemistry 6: 739-749.

68. Goldstein, I. J. \& R. N. IYeR. 1966. Biochim. Biophys. Acta 121: 197-200.

69. IYER, R. N. \& I. J. GoldSTEIN. 1973. Immunochemistry 10: 313-322.

70. Cline, M. J. \& D. C. Livingston. 1971. Nature New Biol. 232: 155-156.

71. Nicolson, G. L. 1971. Nature New Biol. 233: 244-246.

\section{Discussion of the PaPer}

DR. M. A. LEON: Did you say that concanavalin A reacts only with neutral polysaccharides?

DR. GolDSTEIN: No, when I said it reacts only with neutral carbohydrates, I did not mean to indicate that in the presence of an $\mathrm{N}$-acetylated amino sugar the polymer would not react. As far as we know the combining site is not in any way complementary to a charged sugar.

DR. E. A. KabAT: How sure are you that the hydrogens, as distinct from the hydroxyls, are not contributing to the binding energy of your analysis?

DR. GoldsteIN: We are not sure. Our suggestions are based on inhibition studies with fluorine derivatives. I suspect that when the $\mathrm{x}$-ray work is complete we will get the final answer.

Dr. Brewer (Albert Einstein Medical Center, Bronx, New York): I feel that the ultimate understanding of con A specificity will be intimately related to our understanding of its interaction with the $\alpha-(1 \rightarrow 2)$ linked mannose. If you look at the reducing end of your $\operatorname{gal}(1 \stackrel{\alpha}{\rightarrow} 2) \operatorname{man}(1 \stackrel{\alpha}{\rightarrow} 2)$ man trisaccharide, 
the reducing mannose residue is similar in character to the 3,4 , and 6 hydroxyls of a nonreducing mannose.

Of course, this does not completely explain its ability to interact with the more elaborate polysaccharides you later discussed, but I think there is something unique in the $\alpha-1,2$ linkage for the mannose residues, and that the ultimate specificity will be intimately connected with that linkage.

DR. GoldsTEIN: In retrospect the ability of concanavalin $A$ to bind $\alpha-1,2-$ linked mannose appears obvious. We originally suggested that the $\mathrm{C}-3, \mathrm{C}-4$, and C-6 hydroxyl groups must be free, and in 1,2-linked oligosaccharides they are.

Dr. HAGER (Roche Institute of Molecular Biology, Nutley, New Jersey): What part of the con A molecule actually does the linking; what would really be the combining sites? Or what region in the con A molecule is combining with the $\alpha$-1,2-mannose linkage?

DR. GolDSTEIN: I am really not able to answer that.

DR. G. I. PARDoE: This $\alpha-1,2$ is very interesting indeed, because it means that two axial constituents are in close contact. This means that the rest of the mannoside groups are out of place.

DR. GoldsteIn: We have evidence that the $\alpha-1,2$-linked glucose molecule with its axial-equatorial arrangement will also react. 